\title{
PENINGKATAN KEMAMPUAN KELUARGA DALAM MERAWAT KLIEN DIABETES MELLITUS MELALUI SUPPORTIVE GROUP THERAPHY
}

\author{
Novi Widyastuti Rahayu ${ }^{1}$, Maria Putri Sari Utami ${ }^{1}$ \\ ${ }^{1}$ Akademi Keperawatan Notokusumo Yogyakarta \\ Email: nophi_qin12@yahoo.co.id
}

\begin{abstract}
ABSTRAK
Diabetes Melitus merupakan penyakit yang ditandai dengan peningkatan level gula darah. Pengelolaan DM bertujuan untuk mempertahankan kadar glukosa darah dalam rentang normal. Kendala utama pada penanganan DM adalah kejenuhan pasien dalam kepatuhan dalam program pengobatan DM, sehingga diperlukan peran keluarga dalam memberikan dukungan dalam menjalankan program pengobatan DM. Tujuan penelitian ini untuk mengetahui pengaruh Supportive Group Therapy terhadap kemampuan keluarga dalam merawat klien Diabetes Melitus. Penelitian ini adalah penelitian quasy-experimental dengan rancangan pre test- post test design with control group,dengan jumlah sampel 24 responden di Kelurahan Kricak, Tegalrejo, Yogyakarta selama bulan Juni-Oktober 2017. Kemampuan keluarga diukur menggunakan Kuesioner Family Assessment Device (FAD). Hasil menunjukkan bahwa Supportive Group Therapy memberikan pengaruh terhadap peningkatan kemampuan keluarga dalam merawat anggota keluarga dengan diabetes melitus dengan nilai $\mathrm{p}=$ 0,008. Supportive Group Therapy berpengaruh terhadap peningkatan kemampuan keluarga dalam merawat anggota keluarga dengan diabetes melitus.
\end{abstract}

Kata Kunci : Supportive Group Therapy, Diabetes Melitus, Keluarga

\section{INCREASING FAMILY ABILITY IN ACCORDING CLIENTS DIABETES MELLITUS THROUGH SUPPORTIVE GROUP THERAPHY}

\section{ABSTRACT}

Diabetes Mellitus is a disease characterized by increased blood sugar levels. DM management aims to maintain blood glucose levels within the normal range. The main obstacle to DM handling is patient saturation in compliance in DM treatment program, so it is necessary family role in providing support in running DM treatment program. The purpose of this study to determine the effect of Supportive Group Therapy on the ability of families in caring for Diabetes Mellitus clients. This study was a quasy-experimental study with a pre test-post test design with control group design, with a sample of 24 respondents in Kricak, Tegalrejo, Yogyakarta during June-October 2017. Family capability was measured using a Family Assessment Device (FAD) Questionnaire. The results show that Supportive Group Therapy has an effect on the improvement of family ability in caring for family member with diabetes mellitus with $p=0,008$. Supportive Group Therapy affects the increased ability of families in caring for family members with diabetes mellitus.

Keywords: Supportive Group Therapy, Diabetes Mellitus, Family

\section{PENDAHULUAN}

Diabetes Melitus merupakan penyakit yang membutuhkan pengelolaan seumur hidup dalam mengontrol kadar gula darahnya agar dapat meningkatkan kualitas hidup penderita (Arisman, 2013). Menurut hasil konsesus tahun 1997 oleh American Diabetes Association's Expert Committee on the Diagnosis and Classification of Diabetes Melitus menjabarkan 4 kategori utama diabetes melitus, yaitu: DM tipe 1, DM tipe 2, DM tipe lain dan diabetes kehamilan (Corwin, 2009).
Berdasarkan klasifikasi tersebut menurut WHO (2013) jenis DM yang paling banyak diderita dan prevalensinya terus meningkat adalah DM tipe 2 dengan kasus terbanyak yaitu $90 \%$ dari seluruh kasus DM di dunia. Tanda dan gejala DM tipe 2 berlangsung lambat dan progresif, sehingga tidak terdeteksi karena gejala yang dialami pasien sering bersifat ringan seperti kelelahan, iritabilitas, poliuria, polidipsi dan luka yang lama sembuh (Smeltzer \& Bare, 2008). 
Penderita DM yang tidak dapat mengontrol gula darahnya akan memiliki potensi mengalami komplikasi hiperglikemi dimana kondisi ini akan selalu diikuti komplikasi penyempitan vaskuler, yang berakibat pada kemunduran dan kegagalan fungsi organ otak, mata, jantung dan ginjal (Darmono, 2005). Kemampuan tubuh untuk bereaksi dengan insulin dapat menurun pada pasien DM, keadaan ini dapat menimbulkan komplikasi baik akut (seperti diabetes ketoasidosis dan sindrom hiperosmolar nonketotik) maupun kronik. Komplikasi kronik biasanya terjadi dalam jangka waktu 5-10 tahun setelah diagnosa ditegakkan (Smeltzer \& Bare, 2008).

Komplikasi kronik terjadi pada semua organ tubuh dengan penyebab kematian 50\% akibat penyakit jantung koroner dan 30\% akibat penyakit gagal ginjal. Selain itu, sebanyak $30 \%$ penderita diabetes mengalami kebutaan akibat retinopati dan $10 \%$ menjalani amputasi tungkai kaki (Medicastore, 2007). Komplikasi DM lainnya Menurut Soewondo dkk (2010) dalam Purwanti (2013) sebanyak 1785 penderita diabetes melitus di Indonesia yang mengalami komplikasi neuropati $(63,5 \%)$, retinopati (42\%), nefropati $(7,3 \%)$, makrovaskuler $(6 \%)$, mikrovaskuler $(6 \%)$, dan kaki diabetik (15\%). Peningkatan komplikasi dan angka kematian pada penderita DM tipe 2 terjadi jika penderita tidak melakukan terapi pengelolaan DM sesuai dengan saran yang telah diberikan oleh petugas kesehatan (Darmono, 2005). Pengelolaan DM bertujuan untuk mempertahankan kadar glukosa darah dalam rentang normal (Smeltzer\&Bare, 2008).

Pengelolaan DM dikenal dengan sebutan empat pilar DM yaitu penyuluhan atau edukasi, terapi medis, latihan jasmani atau aktivitas fisik dan Diet. Keempat pilar pengelolaan tersebut dapat diterapkan pada semua jenis tipe DM termasuk DM tipe 2. Untuk mencapai fokus pengelolaan DM yang optimal maka perlu adanya keteraturan terhadap empat pilar utama tersebut (PERKENI, 2015). Bentuk keberhasilan pengelolaan DM adalah dengan melaksanakan 4 pilar regimen terapi dengan patuh. Peningkatan kepatuhan pasien DM sangat dipengaruhi oleh adanya peran keluarga, orang-orang terdekat dan lingkungan sekitar. Peran keluarga menjadi sangat penting untuk pasien DM, karena penyakit DM merupakan penyakit yang tidak dapat disembuhkan dan membutuhkan pengelolaan seumur hidup dalam mengontrol kadar gula darah agar meminimalkan komplikasi penyakit DM dan dapat meningkatkan kualitas hidup penderita (Arisman, 2013).

Kendala utama pada penanganan pasien DM adalah kejenuhan pasien dalam kepatuhan dalam program pengobatan DM, sehingga diperlukan peran keluarga dalam memberikan dukungan keluarga dalam menjalankan program pengobatan DM. Hal ini sesuai dengan hasil penelitian Arifin.,et al., (2015) yang mengungkapkan bahwa ada hubungan signifikan antara dukungan keluarga dengan kepatuhan diet DMTipe 2di Poliklinik Penyakit Dalam RSUP Dr. Soeradji Tirtonegoro Klaten. Hal yang sama juga disampaikan oleh Hasil penelitian Hasbi (2012) mengungkapkan bahwa faktor yang paling mempengaruhi penderita DM di Puskesmas Praya, Lombok Tengah dalam melakukan olahraga adalah dukungan keluarga.

Bentuk peran keluarga untuk memberikan dukungan terhadap pasien DM ditunjukkan dengan kemampuan keluarga dalam merawat anggota keluarganya. Kemampuan keluarga yang dipakai menurut teori Bloom yaitu kemampuan kognitif, afektif dan psikomotor (Nasution, 2008). Berdasarkan hal tersebut sangat dibutuhkan pelayanan kesehatan yang berbasis keluarga dan komunitas untuk meningkatkan kemampuan keluarga dalam merawat anggota keluarga dengan DM. Salah satu tindakan keperawatan yang dapat dilakukan untuk meningkatkan kemampuan keluarga yaitu terapi kelompok suportif. Terapi kelompok suportif merupakan salah satu bentuk psikoterapi yang secara luas digunakan pada tatanan keluarga sakit dan komunitas didasarkan pada penatalaksanaan psikiatri (Stuart \& Laraia, 2005). Terapi ini dilakukan dengan menggunakan tiga pendekatan dasar: ekspresi perasaan, dukungan sosial, dan keterampilan manajemen kognitif.

Pemberian Terapi kelompok suportif lebih difokuskan pada keluarga dengan DM secara berkelompok dengan pertimbangan bahwa anggota kelompok nantinya dapat saling memberikan dukungan dan informasi untuk kemampuan keluarga dalam merawat anggota 
keluarga dengan DM. Diharapkan dengan terapi kelompok suportif ini mampu mengakomodasi respon negative dan mengatasi masalah kemampuan keluarga dalam merawat anggota keluarga dengan DM yang dialami kelompok. Hal ini sesuai dengan hasil penelitian Bachtiyar, et al (2015) yang menyatakan bahwa terapi kelompok suportif memiliki pengaruh terhadap perubahan harga diri klien TB paru di Kecamatan Umbulsari kabupaten Jember. Hal yang sama juga disampaikan oleh hasil penelitian Dewi, et al (2012) yang menjelaskan bahwa terapi kelompok suportif yang diberikan mampu menurunkan tingkat ansietas keluarga selama merawat anak tungrahita.

\section{METODE}

Penelitian ini merupakan penelitian kuantitatif. dengan desain penelitian yang digunakan adalah quasi eksperimen dengan rancangan pre test - post test control group. Populasi pada penelitian ini adalah semua keluarga yang mempunyai anggota keluarga dengan diagnosis medis DM Tipe II. Tehnik pengambilan sampel dengan cara consecutive sampling. Jumlah responden yang terlibat dalam penelitian ini ada 24 sampel. Alat pengumpulan data pada penelitian ini adalah kuesioner Family Assessment Device (FAD) yang dikembangkan berdasarkan konsep McMaster Model of Family Functioning (Epstein, et al., 1983). Penelitian dilaksanakan setelah melalui prosedur kaji etik dan mendapatkan pernyataan lulus uji etik dari lembaga etik.

\section{HASIL}

Hasil penelitian ini menjelaskan tentang gambaran penelitian "supportive group therapy untuk keluarga dalam merawat klien diabetes melitus di Kelurahan Kricak Tegalrejo Yogyakarta. Penjelasan hasil penelitian yang dilakukan dapat dilihat pada tabel 1.

Tabel 1.

Distribusi Umur, jenis kelamin, pekerjaan, pendidikan, hubungan dengan pasien dan lama merawat pasien dengan $\mathrm{DM}(\mathrm{n}=24)$

\begin{tabular}{|c|c|c|c|c|c|c|c|}
\hline \multirow[t]{2}{*}{ Variabel } & \multirow[t]{2}{*}{ Kategori } & \multicolumn{2}{|c|}{$\begin{array}{c}\text { Kelompok } \\
\text { Intervensi }(n=12)\end{array}$} & \multicolumn{2}{|c|}{$\begin{array}{c}\text { Kelompok } \\
\text { Kontrol }(\mathrm{n}=12)\end{array}$} & \multirow{2}{*}{$\begin{array}{c}\text { Total } \\
\mathrm{f}\end{array}$} & \multirow{2}{*}{$\begin{array}{c}\text { Persen } \\
\%\end{array}$} \\
\hline & & $\mathrm{F}$ & $\%$ & $\mathrm{f}$ & $\%$ & & \\
\hline \multirow[t]{3}{*}{ Umur } & $27-41$ tahun & 4 & 33,3 & 4 & 33,3 & 8 & 33.3 \\
\hline & $42-52$ tahun & 4 & 33,3 & 2 & 16,7 & 6 & 25.0 \\
\hline & 53-67 tahun & 4 & 33,3 & 6 & 50 & 10 & 41.7 \\
\hline \multirow[t]{2}{*}{ Jenis kelamin } & Laki - laki & 4 & 33,3 & 4 & 33,3 & 8 & 33.3 \\
\hline & Perempuan & 8 & 66,7 & 8 & 66,7 & 16 & 66.7 \\
\hline \multirow{5}{*}{ Pekerjaan } & Buruh & 0 & 0 & 1 & 8,3 & 1 & 4.2 \\
\hline & IRT & 6 & 50 & 4 & 33,3 & 10 & 41.7 \\
\hline & Pensiunan & 1 & 8,3 & 2 & 16,7 & 3 & 12.5 \\
\hline & Tidak bekerja & 1 & 8,3 & 2 & 16,7 & 3 & 12.5 \\
\hline & Wiraswasta & 4 & 33,3 & 3 & 25 & 7 & 29.2 \\
\hline \multirow{6}{*}{ Pendidikan } & Tidak sekolah & 0 & 0 & 1 & 8,3 & 1 & 4.2 \\
\hline & SD & 0 & 0 & 1 & 8,3 & 1 & 4.2 \\
\hline & SMP & 3 & 25 & 4 & 33,3 & 7 & 29.2 \\
\hline & SMA & 7 & 58,3 & 4 & 33,3 & 11 & 45.8 \\
\hline & Sarjana & 1 & 8,3 & 2 & 16,7 & 3 & 12.5 \\
\hline & Diploma & 1 & 8,3 & 0 & 0 & 1 & 4.2 \\
\hline \multirow{3}{*}{$\begin{array}{l}\text { Hubungan dengan } \\
\text { penderita }\end{array}$} & Anak & 5 & 41,7 & 5 & 41,7 & 10 & 41.7 \\
\hline & Istri & 5 & 41,7 & 3 & 25 & 8 & 33.3 \\
\hline & Suami & 2 & 16,7 & 4 & 33,3 & 6 & 25.0 \\
\hline \multirow{5}{*}{ Lama merawat } & $1-3$ tahun & 3 & 25 & 8 & 66,6 & 11 & 45.8 \\
\hline & 4-6 tahun & 4 & 33,3 & 1 & 8,3 & 5 & 20.8 \\
\hline & 7-9 tahun & 1 & 8,3 & 1 & 8,3 & 2 & 8.3 \\
\hline & $10-12$ tahun & 3 & 25 & 1 & 8,3 & 4 & 16.7 \\
\hline & 13-15 tahun & 1 & 8,3 & 1 & 8,3 & 2 & 8.3 \\
\hline
\end{tabular}


Tabel 2.

Perbedaan kemampuan keluarga Antara Kelompok Intervensi dan Kontrol Sesudah Terapi supportive group $(n=24)$

\begin{tabular}{ccccc}
\hline Variabel & Kelompok & $\mathrm{n}$ & Mean & P value \\
\hline Kemampuan & Intervensi & 12 & 16,29 & \multirow{2}{*}{0,008} \\
keluarga & Kontrol & 12 & 8,71 & \\
\hline
\end{tabular}

Berdasarkan tabel 2 diketahui bahwa terdapat perbedaan kemampuan keluarga dalam merawat klien dengan diabetes melitus antara kelompok kontrol dan kelompok intervensi dengan $\mathrm{p}$ value $<0,05$.

\section{PEMBAHASAN}

\section{Karakteristik Responden}

Rata-rata usia keluarga pada kelompok intervensi dan kontrol adalah 53-67 tahun 10 orang $(41,7 \%)$. Usia keluarga pada pasien DM merupakan usia yang sudah matang dalam pengalaman hidup dan kematangan jiwanya dengan peranan sebagai caregiver utama. Usia seseorang berhubungan dengan keputusan untuk menggunakan pelayanan kesehatan dimana semakin bertambah usia seseorang maka semakin besar keyakinannya untuk mencari pertolongan ke fasilitas kesehatan (Stuart \& Laraia, 2005).

Distribusi jenis kelamin sebagian besar perempuan, yaitu 10 orang $(66,7 \%)$. Hasil ini sesuai dengan penelitian Suwardiman (2011), yang menjelaskan bahwa keluarga pasien yang berperan sebagai caregivers utama adalah berjenis kelamin perempuan $(59,5 \%)$. Hal ini seiring dengan pendapat Robinson (1998) dalam Friedman (2010) kondisi dimana anggota keluarga khususnya perempuan memang mempunyai peran yang sangat penting sebagai caregiver utama. Dimana perempuan berperan sebagai seorang ibu, ratarata mempunyai ketelatenan dan kesabaran saat merawat keluarga yang sakit.

Distribusi pekerjaan sebagian besar responden adalah bekerja sebagai ibu rumah tangga yaitu 10 orang $(41,7 \%)$. Secara umum pekerjaan ini berhubungan dengan dukungan dan beban keluarga sebagai caregivers utama. Sebagai caregiver utama tentunya memerlukan waktu luang yang cukup, sehingga dapat merawat anggota keluarga dengan DM. Gambaran pendidikan responden dalam penelitian ini sebagian besar tingkat pendidikan keluarga SMA yaitu $11(45,8 \%)$. Tingakt pendidikan lebih bermakna daripada penghasilan dalam menentukan fasilitas kesehatan (Stuart dan Laraia, 2005). Tingkat pendidikan berhubungan dengan pemilihan fasilitas kesehatan yang tepat dalam menentukan program pengobatan dan merawat anggota keluarga dengan DM.

\section{Perbedaan kemampuan keluarga antara kelompok kontrol dan intervensi setelah diberikan supportive group theraphy}

Rata-rata kemampuan keluarga sesudah terapi supportive group (post test) pada kelompok intervensi sebesar 16,29 lebih besar dibandingkan dengan kelompok kontrol yaitu 8,71 . Hasil uji statistik menunjukkan adanya perbedaan kemampuan keluarga pasien DM antara kelompok intervensi dan kelompok kontrol sesudah mendapatkan terapi supportive group dengan ( $p$ value $<0,05$ ). Hasil penelitian ini berfokus pada penyediaan dan membangun sistem pendukung untuk membantu pemecahan masalah secara individu dalam kelompok. Menurut Stuart dan Laraia (2005) dukungan kemampuan diberikan kepada keluarga untuk dapat mencapai atau mempertahankan kondisi kesehatan dengan menceritakan setiap perkembangan yang terjadi dalam keluarga. Hasil penelitian Wahyuningsih (2011) menunjukkan perbedaan signifikan skor kemampuan merawat setelah diberikan terapi suportif. Begitu juga dengan penelitian Widyastuti (2010) menjelaskan bahwa terapi kelompok suportif dapat meningkatkan kemampuan kognitif, afektif dan psikomotor keluarga sebesar 5,00 dengan $\mathrm{p}$ value 0,000 . Berdasarkan kedua hasil penelitian tersebut, sesuai dengan hasil penelitian ini yaitu terjadi peningkatan yang signifikan kemampuan keluarga setelah diberikan supportive group theraphy.

\section{SIMPULAN DAN SARAN Simpulan}

Karakteristik keluarga yang merawat anggota keluarga dengan diabetes melitus sebagian besar berusia 27-41 tahun, sebagian besar 
berjenis kelamin perempuan, dengan pekerjaan ibu rumah tangga, tingkat pendidikan SMA, hubungan dengan penderita sebagai anak, dan lama merawat responden 1-12 tahun. Selain ittu, terdapat perbedaan kemampuan keluarga dalam merawat anggota keluarga dengan diabetes melitus antara kelompok kontrol dan kelompok intervensi.

\section{Saran}

Supportive Group Therapy dapat dibrikan pada keluarga yang merawat anggota keluarga dengan diabetes melitus.

\section{DAFTAR PUSTAKA}

Arifin \& Santi Damyanti. (2015). Hubungan Dukungan Keluarga Dengan Kepatuhan Dietdiabetes Melitus Tipe 2 Di Poli Penyakit Dalam RSUP Dr. Soeradji Tirtonegoro klaten. Jurnal Keperawatan Respati Vol. II No 2 September 2015. http://nursingjurnal.respati.ac.id/index.p hp/JKRY/article/download/170/79.

Arisman. (2013). Obesitas, Diabetes Melitus, dan Dislipidemia: Konsep: Teori, dan Penanganan Aplikatif Seri Buku Ajar Ilmu Gizi. Jakarta: EGC.

Bachtiyar, B., Dewi, Erti., Aini, L. (2015). Pengaruh terapi suportif: kelompok terhadap perubahan harga diri klien TB Paru di Kecamatan Umbulsari. E-Jurnal Pustaka Kesehatan Vol 3 (no.2).

Corwin, EJ (2009), Buku saku patofisiologi, 3 edn, EGC, Jakarta.

Darmono. (2005). Komplikasi Diabetes Mellitus. Penerbit Rineka Cipta. Jakarta

Dewi, Erti., Hamid, A., Mustikasari. (2012). Pengaruh terapi kelompok suportif terhadap tingkat ansietas keluarga dalam merawat anak tunagrahita. Jurnal Keperawatan Soedirman volume 7 No. 1.

Friedman, M. (2010). Keperawatan keluarga teori dan praktek edisi 5.Jakarta:EGC

Hasbi, M. (2012). Analisis Faktor yang Berhubungan dengan Kepatuhan Penderita
Diabetes Melitus dalam Melakukan Olah Raga di Wilayah Kerja Puskesmas Praya Lombok Tengah. Karya Tulis Ilmiah Strata Dua. Fakultas Ilmu Keperawatan. Universitas Indonesia

Medicastore. (2007). Diabetes, sillen killer. Diambil dari http://medicastore.com/diabetes/pada tanggal 20 Februari 2017

Nasution, S. 2008. Berbagai Pendekatan dalam Proses Belajar Mengajar. Bandung: Bumi Aksara

PERKENI, (2015), Pengelolaan dan Pencegahan Diabetes Melitus Tipe 2 di Indonesia, PERKENI, Jakarta.

Purwanti, O.S. (2013). Analisis Faktor-Faktor Risiko Terjadinya Ulkus Kaki pada Pasien Diabetes Mellitus di RSUD DR.Moewardi Surakarta, Prosiding Seminar Ilmiah nasional, ISSN: 23382694.

Smeltzer, S, \& Bare. (2008). Brunner \& Suddarth's Textbook of medical surgical nursing. Philadelpia : Lippincott

Stuart, G.W. \& Laraia, M.T. (2005). Principle and practice of psychiatric nursing.St.Louis:

Suwardiman, . (2011). Hubungan antara dukungan keluarga dengan beban keluarga untuk mengikuti regimen terapeutik pada keluarga klien halusinasi di RSUD Serang Tahun 2011. .http:lib.ui.ac.id/file?file $=$ digital $/ 202803$ $24-T \%$.

Wahyuningsih, S.A.(2011).Pengaruh terapi suportif terhadap kemampuan keluarga merawat klien gagal ginjal kronik (GGK) yang menjalani hemodilisa di rumah sakit PELNI Jakarta. Jakarta.FIKUI

Widyastuti, S.H.(2010).Pengaruh terapi kelompok suportif terhadap kemampuan keluarga dalam melatih "self care" anak tunanetra ganda di SLB G Rawinda di Jakarta. Jakarta: FIKUI. 